\title{
ANTRACNOSE DO CAQUIZEIRO CAUSADA POR Colletotrichum horii: INCIDÊNCIA EM RAMOS, FOLHAS, FLORES E FRUTOS EM CAMPO ${ }^{1}$
}

\author{
RENATO REZENDE YOUNG BLOOD², LUCIANE CRISTINA ROZWALKA ${ }^{3}$, \\ LOUISE LARISSA MAY DE MIO ${ }^{4}$
}

RESUMO - O objetivo deste trabalho foi avaliar a incidência em várias partes da planta e o desenvolvimento da antracnose do caquizeiro causada por Colletotrichum horii nas cultivares Fuyu e Kakimel produzidas sob os sistemas organico e convêncional, respectivamente, nas safras de 2010/2011 e 2011/2012, em Campina Grande do Sul, Paraná, Brasil. Em cada pomar, 10 plantas foram selecionadas aleatoriamente, e 10 ramos do ano por planta, distribuídos ao redor da copa, foram marcados para as avaliações de incidência de antracnose em ramos e folhas, a cada 15 dias. A quantificação de frutos caídos com ou sem sintomas da doença foi a cada 15 dias, durante o período de crescimento de frutos até a colheita, relacionada com a produção total. C. horii em flores foi avaliada em campo e também após incubação no laboratório. Infecção latente foi observada em frutos verdes coletados aos 90; 120 e 150 dias após a floração. Em ambas as safras, observou-se a queda de frutos com sintomas de antracnose entre os meses de janeiro e abril. $C$. horii é capaz de infectar flores, permanecer latente e provocar sintomas de antracnose em frutos imaturos. Frutos colhidos sadios apresentaram sintomas em pós-colheita após a incubação.

Termos para indexação: Diospyros kaki; infecção latente; pós-colheita; Colletotrichum spp.

\section{PERSIMMON ANTHRACNOSE CAUSED BY Colletotrichum horii: INCIDENCE IN BRANCHES, LEAVES, FLOWERS AND FRUITS IN THE FIELD}

\begin{abstract}
The aim of this study was to evaluate the incidence in different parts of the plant and the development of anthracnose caused by Colletotrichum horii persimmon Fuyu and Kakimel cultivars produced under organic and conventional systems, respectively, on growing seasons in 2010/11 and 2011/12, in Campina Grande do Sul, State of Paraná, Brazil. In each orchard, 10 plants were randomly selected and 10 shoots of one year old spread around of the plant canopy were assessed by the incidence of anthracnose on shoots and leaves, every 15 days. It was quantified the fruit dropped with or without symptoms of the disease every 15 days during the growth period to the fruit harvest and compared to total yield. C. horii incidence was assessed in flowers in the field and after incubation in the laboratory. Latent infection was assessed in green fruit collected at 90,120 and 150 days after flowering. In both seasons, there was fruit drop with anthracnose symptoms from January to April. C. horii is able to infect flowers, remain latent and cause symptoms of anthracnose on immature fruits. Harvest health fruit developed symptoms of the disease after postharvest incubation.
\end{abstract}

Index terms: Diospyros kaki; latent infection; postharvest; Colletotrichum spp.

\footnotetext{
${ }^{1}$ (Trabalho 108-14) . Recebido em: 28-03-2014. Aceito para publicação em: 18-11-2014.

${ }^{2}$ Eng. Agr., MSc. em Agronomia (Produção Vegetal), Universidade Federal do Paraná, Setor de Ciências Agrárias, Departamento de Fitotecnia e Fitossanitarismo, Laboratório de Epidemiologia para Manejo Integrado de Doença de Plantas, Rua dos Funcionários, $\mathrm{n}^{\circ}$ 1540, CEP 80035-050, Curitiba - PR, Brasil (UFPR, SCA, DFF, LEMID). E-mail: renatoblood@yahoo.com.br ${ }^{3}$ Eng. Agr., Dra. em Fitopatologia, Pós-doutora (UFPR, SCA, DFF, LEMID). E-mail: luciane.rozwalka@gmail.com ${ }^{4}$ Eng. Agr., Dra. em Fitopatologia, Profa. Dra. Associada, (UFPR, SCA, DFF, LEMID). E-mail: maydemio@ufpr.br
} 


\section{INTRODUÇÃO}

Os principais produtores mundiais de caqui (Diospyros kaki L.), em 2011, foram a China (3.290.100 t), China Mainland (3.200.000 t), República da Korea (390.820 t), Japão (207.500 t) e, e em quinto lugar, o Brasil, com a produção de $154.625 \mathrm{t}$ (FAO, 2011). A produção nacional de caqui concentra-se nas regiões Sul e Sudeste, sendo São Paulo o maior produtor (74.202 t), seguido pelo Rio Grande do Sul (33.795 t), Paraná (16.129 t), Rio de Janeiro (14.986 t), Minas Gerais (10.840 t), Santa Catarina (4.434 t) e Espírito Santo (120 t). $\mathrm{Na}$ região Nordeste, apenas a Bahia produziu $119 \mathrm{t}$ (IBGE, 2012). Embora o caquizeiro seja conhecido pela rusticidade, vigor e produtividade, no Paraná, a produção de caqui apresentou redução de 36,65\%, entre 2006 e 2011. Além da redução na quantidade produzida de 25.460 para 16.129 t, observou-se a redução da área colhida de 1.747 para 1.226 ha e do rendimento médio 14.574 para $13.156 \mathrm{~kg} \mathrm{ha}^{-1}$. Em Campina Grande do Sul, maior município produtor da região metropolitana de Curitiba e do Paraná, a produção de $13.812 \mathrm{t}$ foi drasticamente reduzida para 2.730 t, representando decréscimo de $80,23 \%$, e da área colhida de 812 para 210 há, e do rendimento médio de 17.010 para $13.000 \mathrm{~kg} \cdot \mathrm{ha}^{-1}$ (IPARDES, 2011). Existem relatos de produtores que essa redução de produção, a partir de 2006, pode ser devido à queda de frutos imaturos provocada pela antracnose. Pois a partir desta data, observou-se aumento da queda em relação ao que ocorria naturalmente em campo. Perdas de até $100 \%$ foram observadas em pomares de Campina Grande do Sul, cultivados em sistema convencional ou orgânico. Essa severidade da doença tem ocasionado a erradicação de pomares, motivo de preocupação para produtores que têm a produção de caqui como a principal fonte de renda e para a região metropolitana de Curitiba. Essa região é responsável pela produção de aproximadamente $27,81 \%$ do caqui paranaense, sendo que $45,59 \%$ da produção são provenientes de pequenas propriedades trabalhadas pela agricultura familiar no Paraná (IPARDES, 2011). A antracnose, considerada a doença mais severa do caquizeiro, é causada por espécies do gênero Colletotrichum e, em maior relevância, por Colletotrichum horii B. Weir; P.R. Johnst. (2010). Em pomares de caqui-doce severamente infectados na Coreia do Sul, a severidade da antracnose, causada por $C$. horii, resultou na queda de $46,2 \%$ de frutos doentes, prejuízo econômico considerável (KWON et al., 2013). Em outras regiões produtoras do Brasil, da China, do Japão, da República da Korea, dos Estados Unidos (WILLIAMSON; SUTTON, 2010) e da Espanha (PALOU et al., 2013), a redução na produção de caqui também tem sido atribuída à antracnose causada por Colletotrichum spp. em ramos, folhas (nervura principal e pecíolo), flores (sépala) e principalmente em frutos.

Apesar de a antracnose do caquizeiro já estar relatada há muito tempo no Brasil, os estudos do desenvolvimento da doença em campo e em pós-colheita ainda são escassos. Em pós-colheita, os estudos enfatizam a manutenção da qualidade, avaliando características como firmeza da polpa, $\mathrm{pH}$, coloração da casca, índices de amaciamento e de escurecimento, teores de sólidos solúveis e de acidez titulável, respiração, produção de etileno, além da atividade da enzima 1-aminociclopropano1-carboxílico (ACC) oxidase, de caquis tratados com a aminoetoxivinilglicina (AVG) e o 1-metilciclopropeno (1-MCP) (BRACKMANN et al., 2013) e a adstringência (índice de tanino), firmeza da polpa e distúrbios da epiderme de caquis tratados com 1-metilciclopropeno (1$\mathrm{MCP})$ e/ou gás carbônico $\left(\mathrm{CO}_{2}\right)$ (GARDIN et al., 2012), em armazenamento refrigerado, os quais propiciam o prolongamento da vida pós-colheita, porém sem especificar os patógenos causadores de sintomas após o referido período. A capacidade do patógeno em infectar várias partes da planta, tornando-as potenciais fontes de inóculo, e os danos, mesmo em cultivos convencionais com programa de pulverizações estabelecidos, evidenciam a necessidade de pesquisas sobre o desenvolvimento da antracnose do caquizeiro (MAY DE MIO, L.L. et al, 2015). Tais pesquisas poderão ajudar na determinação de estratégias de manejo químico ou cultural, de modo a evitar que danos resultem na erradicação desta cultura tradicional que, cultivada em pequenas propriedades, apresenta grande importância econômica e social para a região, pela geração de empregos diretos e indiretos. O objetivo deste trabalho foi avaliar o desenvolvimento da antracnose, nas safras de 2010/2011 e 2011/2012, na região de Campina Grande do Sul, por meio da avaliação de incidência da doença em ramos, folhas, flores e frutos, e interferência das variáveis climáticas no desenvolvimento da doença.

\section{MATERIAL E MÉTODOS}

O experimento foi realizado nas safras de 2010/2011 e 2011/2012, em dois pomares localizados no município de Campina Grande do Sul, região metropolitana de Curitiba, no Paraná, sendo um conduzido em sistema orgânico de produção com a cultivar Fuyu, e outro em 
sistema convencional com a cultivar Kakimel, localizados a $25^{\circ} 22^{\prime \prime} 32,8^{\prime} \mathrm{S} / 49^{\circ} 16^{\prime} 23,3^{\prime \prime} \mathrm{W}, 924 \mathrm{~m}$ de altitude e $25^{\circ} 14^{\prime} 36,7^{\prime} \mathrm{S} / 48^{\circ} 58^{\prime}$ '07,9' W, $815 \mathrm{~m}$ de altitude (SAD 69 South American Datum 1969), respectivamente, sob clima subtropical de altitude (Cfb), segundo classificação climática de Köppen. No pomar orgânico de Fuyu (10 anos) de 3,0 ha, em relevo aproximadamente plano, verificou-se a ausência de adubação química e de poda das plantas, sendo a aplicação de calda sulfocálcica a $8 \%$ (Sulfocal), o único tratamento fitossanitário realizado no inverno. No pomar convencional de Kakimel (25 anos) de 3,5 ha, com declividade de aproximadamente $20 \%$, verificou-se a realização de poda para abertura da copa das plantas e tratamento com calda sulfocálcica a $8 \%$ no inverno, poda verde nos meses de novembro e dezembro, de adubação no início da brotação com nitrogênio, fósforo e potássio (NPK 10-10-10) e tratamentos fitossanitários com os fungicidas mancozebe (12-09 e 05-09), tiofanato metílico (20-10 e 7-10), difenoconazol (27-11 e 9-11), metiram + piroxicam (4-1 e 19-12), tebuconazol + trifloxistrobina (28-02 e 30-01), e tiofanato metílico (17-03 e 01-03), durante as safras de 2010/2011 e 2011/2012, respectivamente. Em ambos os pomares, as plantas encontravam-se conduzidas em vaso, com espaçamento de 6,0 x 5,0 $m$ entre linhas e plantas, respectivamente. Em campo, foi avaliada a incidência de antracnose em ramos, folhas e frutos, e em laboratório, a incidência de $C$. horii nas flores, latência de $C$. horii em frutos verdes e incidência de $C$. horii nos frutos em pós-colheita, durante o armazenamento.

Em 10 plantas selecionadas aleatoriamente em cada pomar, evitando-se as plantas da bordadura, 10 ramos do ano, distribuídos aleatoriamente ao redor da copa de cada planta, foram marcados com fitas coloridas para as avaliações de incidência de antracnose desde a floração até a pós-colheita.

Incidência de antracnose em ramos, folhas e flores. Foram avaliados sintomas de antracnose em ramos e folhas, quinzenalmente, desde o início da brotação, que ocorreu em final de agosto de cada ano, até abril do ano seguinte. As flores foram monitoradas nas plantas marcadas em relação ao sintoma visível de infecção por Colletotrichum durante toda a floração, de meados de setembro a final de outubro, em ambas as safras avaliadas. A incidência de $C$. horii em flores foi também avaliada em laboratório para observar infecção em condições favoráveis para o patógeno. Coletaram-se 100 flores completas em cada pomar, de forma aleatória, sendo 10 de cada planta marcada, no final da floração (25-10-2011), na safra de 2011/2012. As flores foram acondicionadas em caixas plásticas tipo Gerbox (11,0 x 11,0 x 3,5 $\mathrm{cm})$ com papel-filtro umedecido em água destilada esterilizada, mantidas em câmara de crescimento a 25 $\pm 2{ }^{\circ} \mathrm{C}$, sob fotoperíodo de 12 horas. A avaliação foi realizada diariamente até a visualização do patógeno em qualquer parte da flor.

Quantificação de frutos caídos com e sem sintomas de antracnose. Para estimar o número de frutos abortados naturalmente, frutos caídos sem sintoma de antracnose de cada ramo marcado foram quantificados a cada 15 dias, observando-se o período do ciclo em que a queda ocorreu. Para a quantificação dos danos causados pela antracnose em cada planta marcada, todos os frutos caídos com sintomas da doença foram contados até o dia da colheita. Na colheita, todos os frutos foram contados para a determinação da produção total de cada planta e relação de danos por abortamento natural e por antracnose.

Infecção latente de $C$. horii em frutos verdes. Para avaliação de infecção latente de $C$. horii, 50 frutos verdes foram coletados aleatoriamente nas 10 plantas marcadas, em cada pomar, aos 90; 120 e 150 dias após plena floração. Os frutos foram desinfestados em $10 \mathrm{~L}$ de solução com $160 \mathrm{~mL}$ de hipoclorito de sódio a $0,525 \%+160 \mathrm{~mL}$ de etanol a $92,5{ }^{\circ} \mathrm{GL}+0,5 \mathrm{~mL}$ de Tween 20 , por 4 minutos, lavados em água destilada e esterilizada, e deixados sobre papel toalha esterilizado para retirar o excesso d'água, acondicionados em sacos plásticos e incubados em freezer $\mathrm{-}-15^{\circ} \mathrm{C}$ por 15 horas, de acordo com a técnica de incubação com congelamento em freezer Overnight Freezing Incubation Technique - ONFIT (LUO; MICHAILIDES, 2001), com modificações. Após incubação no freezer, os frutos foram acondicionados em caixas plásticas sobre papel-filtro umedecido e incubados sob fotoperíodo por 12 horas e temperatura de $25 \pm 2{ }^{\circ} \mathrm{C}$. A incidência de $C$. horii, caracterizada pela esporulação em qualquer parte do fruto, foi avaliada diariamente durante sete dias.

Incidência de antracnose nos frutos de caquizeiro na colheita e em pós-colheita. $\mathrm{Na}$ colheita, os frutos com antracnose das plantas marcadas foram separados e quantificados. Para avaliação de incidência da doença em pós-colheita, 20 frutos em ponto de colheita sem sintomas ou injúrias foram colhidos em cada uma das 10 plantas marcadas em cada pomar. Destes, 10 frutos foram desinfestados com a solução utilizada na técnica 
ONFIT descrita anteriormente, e os outros 10 não foram desinfestados. Os frutos desinfestados e não desinfestados foram acondicionados em caixas plásticas com papel-filtro umedecido e incubados em temperatura ambiente de $25 \pm 2{ }^{\circ} \mathrm{C}$ e fotoperíodo de 12 horas, em prateleiras. As estruturas do patógeno nos frutos foram avaliadas no $9^{\circ}, 13^{\circ}$ e $18^{\circ}$ dias após a colheita.

Correlação entre as variáveis climáticas e a incidência de antracnose. Para avaliar a interferência do clima sobre a doença, dados climáticos relativos à temperatura média $\left(\mathrm{T}^{\circ} \mathrm{C}\right)$, umidade relativa média (UR) e precipitação acumulada $(\mathrm{Pp})$, registrados na Estação Climatológica de Piraquara/Pinhais do IAPAR/SIMEPAR (Código ANA - 02549041), localizada no município de Pinhais, com $25^{\circ} 25^{\prime}$ de latitude sul, $49^{\circ} 08^{\prime}$ de longitude oeste e altitude de $930 \mathrm{~m}$, foram fornecidos pelo Sistema Meteorológico do Paraná (SIMEPAR). Foram feitas correlações entre as variáveis climáticas $\mathrm{T}^{\circ} \mathrm{C}$, UR (\%) e $\mathrm{Pp}$ (mm) (média dos 10 dias anteriores a cada período avaliado) e o número de frutos caídos sem e com sintoma; e entre o número de dias após a floração, com o número de frutos caídos sem e com sintoma. As análises foram realizadas pelo programa $R$ Development Core Team (2010).

\section{RESULTADOS E DISCUSSÃO}

O agente etiológico da antracnose do caquizeiro na região de Campina Grande do Sul, $C$. horii, provocou sintomas em ramos, folhas, flores e frutos, os quais se constituem em fontes de inóculo durante toda a safra e também entre as safras. Assim, a eliminação dessas fontes de inóculo e técnicas de controle constituem-se em medidas essenciais no manejo do pomar, visando à redução da doença.

A queda mais acentuada dos frutos jovens de caqui foi relacionada com a infecção do patógeno em frutos, uma vez que, nos frutos caídos, observou-se sintoma típico de antracnose em época diferente da queda natural de frutos assintomáticos. O patógeno pode permanecer latente em frutos de caqui e, neste caso, expressar sintomas em pós-colheita durante o armazenamento dos frutos colhidos sadios.

Incidência de $C$. horii em ramos e folhas. Durante o período de avaliação, não foram observados sintomas típicos de antracnose nos ramos e folhas marcados; entretanto, lesões foram observadas em ramos mais jovens e também em ramos ladrões, da mesma forma como em outras folhas, em incidência baixa na planta como um todo. Em flores avaliadas nas plantas marcadas, não foram observados sintomas da doença nas safras avaliadas. Diante disso, apenas na $2^{\mathrm{a}}$ safra do estudo, flores foram coletadas e avaliadas em laboratório quanto à presença e/ou infecção do patógeno.

Infecção latente de $C$. horii em flores de caquizeiro. A infecção de $C$. horii em flores de caquizeiro das cultivares Fuyu e Kakimel foi confirmada pela esporulação em ovários e na base das sépalas, aos sete dias após incubação (Figura 1A). A incidência média de $C$. horii em flores de caqui foi de $36 \%$ em cv. Fuyu (variando de 20 a 50\% entre as plantas) e $61 \%$ em cv. Kakimel (variando de 20 a $100 \%$ ) na safra 2011/2012.

Quantificação de frutos caídos com e sem sintomas de antracnose. Na cultivar Fuyu, a queda de frutos sem sintomas de antracnose por abortamento natural iniciou aos 40 dias e estabilizouse ao redor dos 100 dias após a floração, em ambas as safras (Figura 2A e 2B). Na cv. Kakimel, o início da queda foi observado próximo aos 70 dias após a floração na safra de 2010/2011 e aos 40 dias na safra seguinte, tendo-se estabilizado entre 120 e 140 dias após o início da floração ou da plena floração, respectivamente (Figuras $2 \mathrm{C}$ e $2 \mathrm{D}$ ).

$\mathrm{O}$ abortamento natural de caquis também foi observado por Corsato et al. (2005) na cultivar Rama-Forte, que iniciado aos quatro dias após o início do florescimento, gerou em dois picos distintos a queda de aproximadamente $25 \%$ e $39 \%$ dos frutos aos 21 e 48 dias após o início do florescimento, respectivamente, restando ao final dos dois picos de queda aproximadamente $45 \%$ da frutificação inicial. Gin Razzouk (2007) observou a queda natural dos frutos das cultivares Rubi, Taubaté, Toote e Fuyu, aos 42 dias após o florescimento ( $1^{\mathrm{a}}$ quinzena de dezembro), das cultivares Pomelo, Rama-Forte, Giombo e Suruga, dos 63 aos 98 dias após o florescimento (início de dezembro ao início de janeiro), e da cv. Jirô com o pico de queda mais precoce: apenas uma semana após o florescimento.

A queda de frutos com sintomas de antracnose nas cultivares Fuyu e Kakimel, na safra de 2010/2011, teve início ao redor dos 120 dias após início da floração ou da plena floração, para as duas cultivares, sendo observado na cv. Fuyu o aumento do número de frutos caídos até a colheita aos 150 dias e redução na cv. Kakimel também até a colheita aos 180 dias. Na safra de 2011/2012, o início da queda foi ao redor de 80 dias após a floração, nas duas cultivares, observando-se número constante de frutos caídos de Fuyu (Figuras 2E e F) e, aumento acentuado de frutos 
caídos de cv. Kakimel até a colheita (Figuras 2G e H).

$\mathrm{O}$ abortamento e/ou a queda de frutos apresenta-se como um evento natural de raleio nos caquizeiros, desde que não persista por todo o ciclo da cultura, como observado nos pomares de cv Fuyu e cv. Kakimel neste estudo.

Os danos totais causados pela queda de frutos com sintoma de antracnose foram na cv. Fuyu de 7,46 e $19,48 \%$ e na cv. Kakimel de 4,31 e 5,93\%, nas safras de 2010/2011 e 2011/2012, respectivamente.

Em relação aos frutos caídos com sintoma de antracnose, verificou-se que a queda pode ocorrer a partir de 80 dias após a floração, no mês de janeiro, onde são comuns temperaturas médias acima de 20 ${ }^{\circ} \mathrm{C}$ e alta precipitação acumulada, indicando que a epidemia está diretamente relacionada com as condições climáticas; todavia, os dados de correlação não confirmaram esta hipótese neste caso.

No sul da China, maior produtor mundial da fruta, os sintomas da antracnose, causada por $C$. horii são geralmente encontrados em ramos novos, infectados antes da lignificação e nos frutos principalmente no período de alongamento para o amadurecimento, sendo raros em folhas, porém podem ocorrer no pecíolo, nervura principal e na sépala. Em pomares de alta densidade de plantas e ramos, em ambientes chuvosos e com grande formação de orvalho, a antracnose ocorre com maior severidade (YANG et al., 2009).

Nas duas safras e nas duas cultivares, aos 120 dias após a floração, a incidência de Colletotrichum sp. latente em frutos verdes foi maior. Neste período, segundo Mowat e George (1994), o caquizeiro está no estágio II de desenvolvimento, transição entre o estágio I associado ao processo de divisão e diferenciação celular, e o III, de elongação e maturação fisiológica, que por ser o estágio de menor duração (20 a 40 dias) e apresentar transformações bioquímicas, provavelmente, favorece a expressão do patógeno latente.

Infeç̧ão latente de $C$. horii em frutos verdes. A técnica ONFIT demonstrou-se eficiente no controle de fatores que controlam a expressão de sintomas e sinais em frutos verdes, propiciando a observação da esporulação de $C$. horii latente em cv. Fuyu (Figura 1B) e cv. Kakimel (Figura 1C). A maior incidência de $C$. horii latente em frutos verdes, representada pelos maiores valores da área abaixo da curva de progresso da doença (AACPD), foi observada nos frutos de cv. Fuyu e cv. Kakimel coletados aos 120 dias após a plena floração, nas safras de 2010/2011 e 2011/2012 (Tabela 1). Nos frutos coletados aos 120 e 150 dias após plena floração, observou-se C. horii latente em 78\% dos frutos de cv. Fuyu nas duas avaliações, e em $61 \%$ e $37 \%$ dos frutos de cv. Kakimel, respectivamente. Na safra de 2011/2012, a infecção latente em frutos verdes foi inferior à safra anterior, em ambas as cultivares, sendo observada a latência em 9;20 e $17 \%$, e $24 ; 30$ e $14 \%$, dos frutos de cv. Fuyu e cv. Kakimel coletados aos 90; 120 e 150 dias, após plena floração, respectivamente.

Incidência de antracnose nos frutos de caquizeiro na colheita e em pós-colheita. Nas 10 plantas marcadas, nas safras de 2010/2011 e 2011/2012, foram colhidos 2.199 e 1.151 frutos sadios na cv. Fuyu e 7.283 e 5.497 na cv. Kakimel, respectivamente. O número de frutos com antracnose na colheita foi inferior a $1 \%$ (dados não apresentados), sendo computados na avaliação de dano na produção somados aos frutos caídos. Em ambas as safras avaliadas, a produtividade média foi de 10 t.ha $^{-1}$ e peso médio do fruto de $117 \mathrm{~g}$ na cultivar Fuyu e 40 t.ha ${ }^{-1}$ e peso médio do fruto de $235 \mathrm{~g}$ na cultivar Kakimel. Esta diferença pode ser atribuída às idades, cultivares e manejos totalmente diferentes. A incidência do patógeno, aos 18 dias após a colheita, foi observada nas cultivares Fuyu e Kakimel, nos dois ciclos. Na cv. Fuyu, na safra de 2010/2011, a incidência foi de $12 \%$ e $4 \%$, para frutos desinfestados e não desinfestados, respectivamente, e em 2011/2012, foi de 4 e 7\%. Na cv. Kakimel, na safra de 2010/2011, a incidência foi de $3 \%$ e 5\%, e em $2011 / 2012$, de $1 \%$ e $0 \%$, em frutos desinfestados e não desinfestados, respectivamente (Tabela 2).

Em pós-colheita, foi observado que a doença esteve presente em índices variáveis, causando danos mais significativos no pomar orgânico da cultivar Fuyu, provavelmente devido à ausência de tratamentos fitossanitários. Nesta cultivar, o aumento da doença no campo refletiu diretamente na qualidade do fruto na pós-colheita. Em póscolheita, a incidência do patógeno nos frutos de cv. Fuyu (somando desinfestados e nãodesinfestados), estimada em $16 \%$ e $11 \%$, foi superior à incidência observada em cv. Kakimel, de $11 \%$ e 1\%, nas safras de 2010/2011 e 2011/2012, respectivamente. Em ambas as safras, a porcentagem de frutos caídos com sintomas em cv. Fuyu (7,46\% e 19,48\%) foi superior à de cv. Kakimel (4,31\% e 5,93\%). A maior incidência do patógeno causando danos no pomar orgânico de cv. Fuyu pode ser atribuída à ausência de manejo de poda, de adubação e de tratamentos fitossanitários, favorecendo a disseminação de inóculo na região. Xie et al. (2010) relataram a incidência de antracnose em caqui em pós-colheita 
causando danos, porém sem quantificá-la.

Correlação entre as variáveis climáticas e incidência de antracnose. Considerando as variáveis climáticas UR, $\mathrm{T}^{\circ} \mathrm{C}$ e $\mathrm{Pp}$, nos dez dias anteriores de cada período avaliado, verificou-se que não houve correlação entre essas variáveis, o número de frutos caídos sem sintoma e o número de frutos caídos com sintomas, nas cultivares Fuyu e Kakimel. A Pp foi maior na safra de 2010/2011. Entretanto, em ambas as cultivares, a correlação positiva entre dias após a floração e o número de frutos caídos com sintomas foi observada indicando que quanto maior o número de dias após a floração, maior o número de frutos caídos com sintoma. Para a cv. Fuyu, o coeficiente de correlação de Pearson foi de 0,61 e valor de $p=$ 0,0030 e cv. Kakimel, coeficiente de correlação de Pearson de 0,58 e valor de $p=0,0037$. Comparandose os resultados obtidos de incidência de $C$. horii em flores, frutos verdes aos 90; 120 e 150 dias com o número de frutos sintomáticos caídos e o dano em frutos em pós-colheita, observou-se que apenas uma porcentagem reduzida da população do patógeno foi capaz de causar sintomas. Uma explicação para tal redução baseia-se na possibilidade de grande parte da população de Colletotrichum latente sobreviver endofiticamente nos frutos, sem causar sintomas ou qualquer dano aparente, nas condições climáticas presentes. A fase latente representa uma condição específica, onde os fungos podem desenvolver sintomas ou causar a mudança na fisiologia da planta hospedeira (ROMERO et al., 2001). Colletotrichum gloeosporioides tem sido comumente isolado como endofítico de várias espécies de plantas, como, por exemplo, bananeira (Musa acuminata L.) (PHOTITA et al., 2001), em cacau (Theobroma cacao) (MEJÍA et al., 2008), dentre outros.

Por definição, um endofítico não pode ser considerado a causa da doença, não sendo nem sempre clara a distinção entre patógeno e endofítico (SINCLAIR; CERKAUSKAS, 1996 citado por PHOTITA et al., 2004); entretanto, gêneros e espécies que podem causar doença são normalmente isolados e identificados como endofíticos (PHOTITA et al., 2004). Mudança na suscetibilidade do hospedeiro, causada por excesso de umidade ou deficiência de nutrientes, pode induzir a transição de um modo de vida para o outro e determinar a duração do período durante o qual um indivíduo permanecerá no mesmo modo de vida (FISHER; PETRINI, 1992 citado por HYDE et al., 2009).

Conhecido como agente etiológico da antracnose também em soja (Glycine max), Colletotrichum sp. foi isolado como endofítico em plantas aparentemente sadias dessa cultura, cultivadas em campo e em estufa, por Pimentel et al. (2006). Os autores inferiram que a presença do patógeno como endofítico poderia ter ocorrido em função do período de amostragem muito curto para permitir que os sintomas de antracnose se manifestassem, porém, em plantas mais velhas, sintomas também não foram observados; que os isolados não eram patogênicos; que os isolados eram patogênicos, mas que esses foram impedidos de desenvolver a antracnose pelo complexo sistema de endófitos no interior das plantas.

Freeman e Rodrigues (1993), citados por Pimentel et al. (2006), relataram que, em Colletotrichum, endófito e estirpes patogênicas podem ser obtidos a partir de cada um dos outros por um único evento de mutação. A associação filogenética de espécies endofíticas e saprófitas realizada por Promputtha et al. (2007) indicou que os isolados podem ter origem semelhante e têm a capacidade de mudar suas estratégias ecológicas durante a senescência do hospedeiro. Assim, várias hipóteses surgem na tentativa de entender por que a alta incidência do patógeno latente em frutos verdes, aos 90; 120 e 150, dias não implica alta incidência de frutos caídos com sintomas na colheita e em danos em pós-colheita. Dentre os possíveis fatores responsáveis pela mudança do modo de vida de endofítico para patogênico, e/ou para desencadear a expressão do patógeno latente, foram relacionados: alteração das condições físico-químicas pelo congelamento durante aplicação da técnica ONFIT e quantidade de tanino e outros compostos fenólicos nos diferentes estádios de maturação, considerando que a infecção tenha ocorrido no período de floração. Considerandose a exposição dos frutos e a técnica ONFIT, supõe-se que a menor incidência do patógeno verificada nos frutos verdes coletados aos 90 dias ocorreu em função do tempo de congelamento, que não foi suficiente para reduzir a quantidade de tanino e/ou outros compostos fenólicos em cv. Kakimel ou compostos fenólicos, como os ácidos gálico e clorogênico, e catequina em cv. Fuyu, os quais podem inibir o desenvolvimento do microrganismo patogênico e do endofítico, propiciando apenas a expressão de alguns patogênicos menos suscetíveis ou mais resistentes a esses compostos. A maior incidência, em ambas as cultivares, resultando em maior área abaixo da curva de progresso da doença, aos 120 dias em relação aos 90 e 150 dias, pode ser resultante de um estresse decorrente do congelamento e da quantidade de tanino e/ou de compostos fenólicos, o qual propiciou a expressão de maior número de endofíticos e patogênicos ou a alteração do estado de latência de ambos ou ainda a mudança de endofítico 
em patogênico. Aos 150 dias, próximo da colheita, supõe-se que as quantidades de tanino e/ou outros compostos fenólicos em cv. Kakimel, e de compostos fenólicos, como os ácidos gálico e clorogênico, e catequina em cv. Fuyu permitiram apenas o desenvolvimento dos patogênicos, não se tendo apresentado juntamente com o congelamento como um fator de estresse como aos 120 dias. Portanto, parece que a expressão (esporulação) da população endofítica e da patogênica depende de mudanças físico-químicas como as alterações na quantidade de pectina e de tanino e/ou outros compostos fenólicos que ocorrem nos estádios de maturação dos frutos. Isto pode favorecer ou não o desenvolvimento dessas, sendo para a população endofítica necessário também um estresse como o congelamento. A menor incidência de $C$. horii em frutos de cv. Kakimel pode ser atribuída à presença de taninos, pois essa pertence ao grupo dos caquis taninosos (moles) que precisam de destanização para serem consumidos em função da elevada adstringência causada pelo tanino, enquanto a cultivar Fuyu pertence ao grupo dos caquis-doces (duros) caracterizados pela ausência de tanino. Taira et al. (1998) observaram à redução da adstringência na polpa de caqui (cv. Hiratanenashi) congelada lentamente em freezer convencional devido a redução de taninos solúveis durante o descongelamento, tornando-se essa quase não adstringente. A adesão de taninos solúveis, liberados a partir de células de taninos durante o descongelamento e que se tornaram insolúveis em contato com fragmentos de paredes celulares e membranas plasmáticas, pode ser um dos fatores responsáveis pela redução de adstringência em caqui. Ressaltaram ainda que a redução da adstringência em caqui congelado e descongelado, provavelmente, não está relacionada a mudanças nas substâncias pécticas, que mudaram pouco durante e após o descongelamento.

A expressão de sintomas pelo Colletotrichum patogênico, em ambas as cultivares, pode ser atribuída também à alteração na estrutura de parede, como a redução de pectina no processo de maturação, favorecendo a colonização do patógeno; entretanto, estudos mais aprofundados neste tema devem ser realizados. Cutillas-Iturralde et al. (1993) observaram a redução da pectina de $46 \%$ do peso seco em frutos imaturos para $20 \%$ em frutos maduros, e a redução de polissacarídeos. Essa redução implica menor reserva energética e perda de estrutura que induz o patógeno a se desenvolver ou o endofítico a mudar seu modo de vida para patogênico. Em árvores de clima temperado, taninos e compostos fenólicos relacionados preservam o cerne da degradação por fungos e inibem hidrolases extracelulares de patógenos invasores, impedindo assim seu rápido desenvolvimento na planta (LATTANZIO et al., 2006). Na cultivar Fuyu, a menor incidência em pós-colheita pode estar relacionada à redução de compostos fenólicos. Baltacioğlu e Artik (2013) observaram a redução dos ácidos gálico e clorogênico e catequina em caqui cv. Fuyu durante o período de armazenamento a $22{ }^{\circ} \mathrm{C}$. Chen et al. (2006) observaram que a inoculação da suspensão de conídios de C. kahawae (J.M. Waller; P.D. Bridge) contendo catequina ou epicatequina abundante no pericarpo de baga de café verde $\left(1,2 \mathrm{mg} \cdot \mathrm{mL}^{-1}\right)$ não afetou a germinação de conídios ou a formação de apressórios. Entretanto, a melanização do apressório, essencial para a penetração na cutícula da planta, foi completamente inibida, e a infecção, reduzida a $30 \%$ do controle não tratado, concluindo que esses compostos fenólicos podem prevenir a doença da baga do café pela inibição da melanização do apressório de C. kahawae. Villarino et al. (2011) observaram que o ácido clorogênico e o ácido neoclorogênico, identificados como os principais compostos fenólicos na polpa e na casca de três cultivares de pêssego, conferiram alta resistência dos frutos à infecção de Monilinia laxa (Aderh.; Ruhl.) Honey, agente etiológico da podridão-parda, e a redução desses compostos fenólicos devido ao processo de maturação, responsável pelo aumento da suscetibilidade à infecção do patógeno. Este aumento de suscetibilidade com a maturação foi também observado em frutos verdes de caqui.

Pela avaliação da esporulação em caqui, não foi possível determinar as populações endofítica e patogênica, pois não existe distinção visual entre ambas. Entretanto, alguns isolados obtidos a partir de frutos verdes de caqui após a técnica ONFIT, quando inoculados em caquis maduros, não produziram sintomas, demonstrando-se não patogênicos sem ferimento e, possivelmente, mantendo seu modo de vida endofítico (dados não apresentados). Photita et al. (2004) observaram que C. gloeosporioides (Penz.) Sacc. isolado como endofítico de folhas, pecíolos e pseudocolmos sadios assintomáticas de bananeira, quando inoculado com micélio e conídio em folhas de bananeira sadias, com e sem ferimento, também não produziram sintomas.

Embora o controle químico seja considerado a principal estratégia no manejo de doenças em frutíferas, para o controle da antracnose na cultura do caquizeiro, constitui-se num entrave devido à falta de produtos registrados. O suporte fitossanitário insuficiente tem induzido o uso irregular e indiscriminado de produtos não registrados, como observado no pomar conduzido em sistema 
convencional com a cultivar Kakimel. No programa de pulverização da propriedade, dentre os seis produtos utilizados, apenas um se encontra registrado para a cultura do caquizeiro para o controle de Cercospora kaki, e os demais, para controle de espécies de Colletotrichum, exceto para C. horii (AGROFIT, 2013).

Intensificar as pesquisas de eficiência de fungicidas para o controle da antracnose em caquizeiro, bem como facilitar o processo de registro desses produtos via Minor Crops constitui- se num passo imprescindível e urgente para que um programa de pulverização seja elaborado para prevenir, principalmente a infecção nas fases iniciais de desenvolvimento do caquizeiro e durante todo o ciclo.

Os danos causados pelo patógeno nas duas safras e os relatos de prejuízos frequentes por produtores de caqui do Paraná, em função da queda acentuada de frutos em alguns anos, comprometem a produção e ameaçam o futuro da produção de caqui no município.

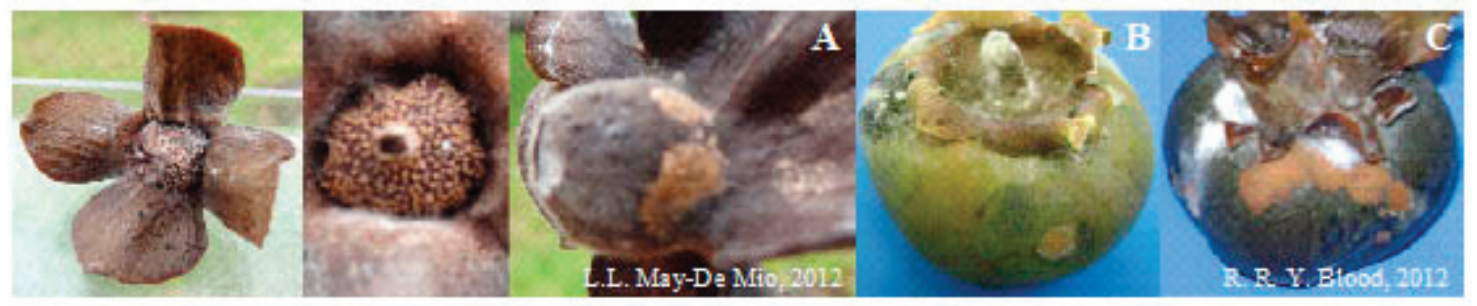

FIGURA 1- Infecção de Colletotrichum horii após incubação em flores de caqui da cultivar Fuyu (A) e esporulação de $C$. horii em fruto resultante da infecção latente nas cultivares Fuyu (B) e Kakimel (C) submetidos à técnica overnight freezing incubation technique - ONFIT obtidos da região metropolitana de Curitiba, no Paraná, Brasil.

TABELA 1 - Infecção latente de Colletotrichum horii em frutos de caqui cv. Fuyu e cv. Kakimel cultivados sob sistema orgânico e convencional, respectivamente, coletados aos 90; 120 e 150 dias, após plena floração, em Campina Grande do Sul, região metropolitana de Curitiba, no Paraná, Brasil.

\begin{tabular}{|c|c|c|c|c|c|c|c|c|c|c|}
\hline \multirow{3}{*}{$\begin{array}{l}\text { Dias de } \\
\text { Câmara } \\
\text { úmida }\end{array}$} & \multicolumn{5}{|c|}{ cv. Fuyu } & \multicolumn{5}{|c|}{ cv. Kakimel } \\
\hline & \multicolumn{2}{|c|}{$2010 / 2011$} & \multicolumn{3}{|c|}{$2011 / 2012$} & \multicolumn{2}{|c|}{$2010 / 2011$} & \multicolumn{3}{|c|}{$2011 / 2012$} \\
\hline & 120 & 150 & 90 & 120 & 150 & 120 & 150 & 90 & 120 & 150 \\
\hline 1 & 0 & 0 & 0 & 0 & 0 & 0 & 0 & 0 & 0 & 0 \\
\hline 2 & 0 & 0 & 0 & 0 & 0 & 0 & 0 & 0 & 0 & 0 \\
\hline 3 & 0 & 0 & 0 & 0 & 0 & 1,7 & 0 & 0 & 0 & 0 \\
\hline 4 & 47 & 9 & 0 & 0 & 0 & 39 & 10 & 0 & 0 & 4 \\
\hline 5 & 78 & 57 & 0 & 20 & 10 & 61 & 29 & 0 & 30 & 14 \\
\hline 6 & 78 & 69 & 9 & 20 & 17 & 61 & 35 & 17 & 30 & 14 \\
\hline 7 & 78 & 78 & 9 & 20 & 17 & 61 & 37 & 24 & 30 & 14 \\
\hline $\mathrm{AACPD}^{1}$ & 242,0 & 173,7 & 14,0 & 50,0 & 39,4 & 193,2 & 104,7 & 28,7 & 75,0 & 39,0 \\
\hline
\end{tabular}

${ }^{1}$ AACPD Área abaixo da curva do progresso da doença 

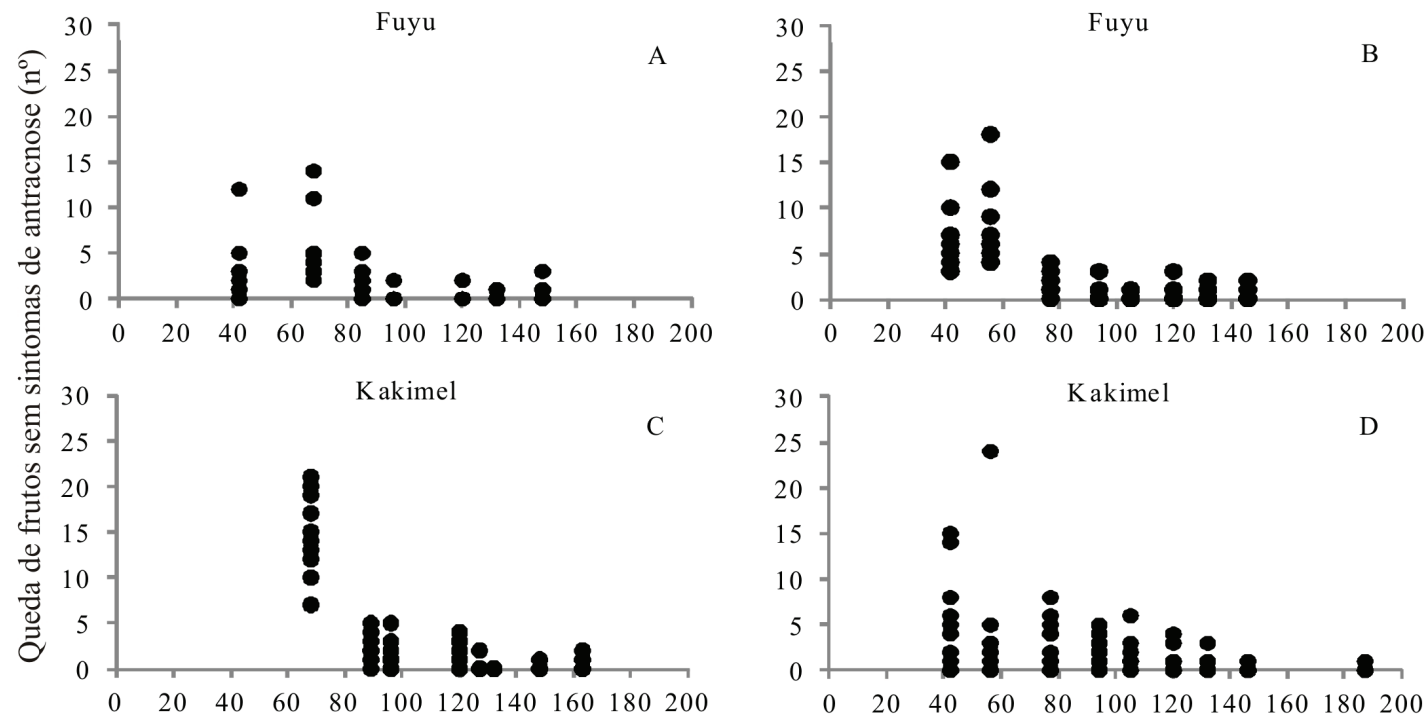

Dias após a floração
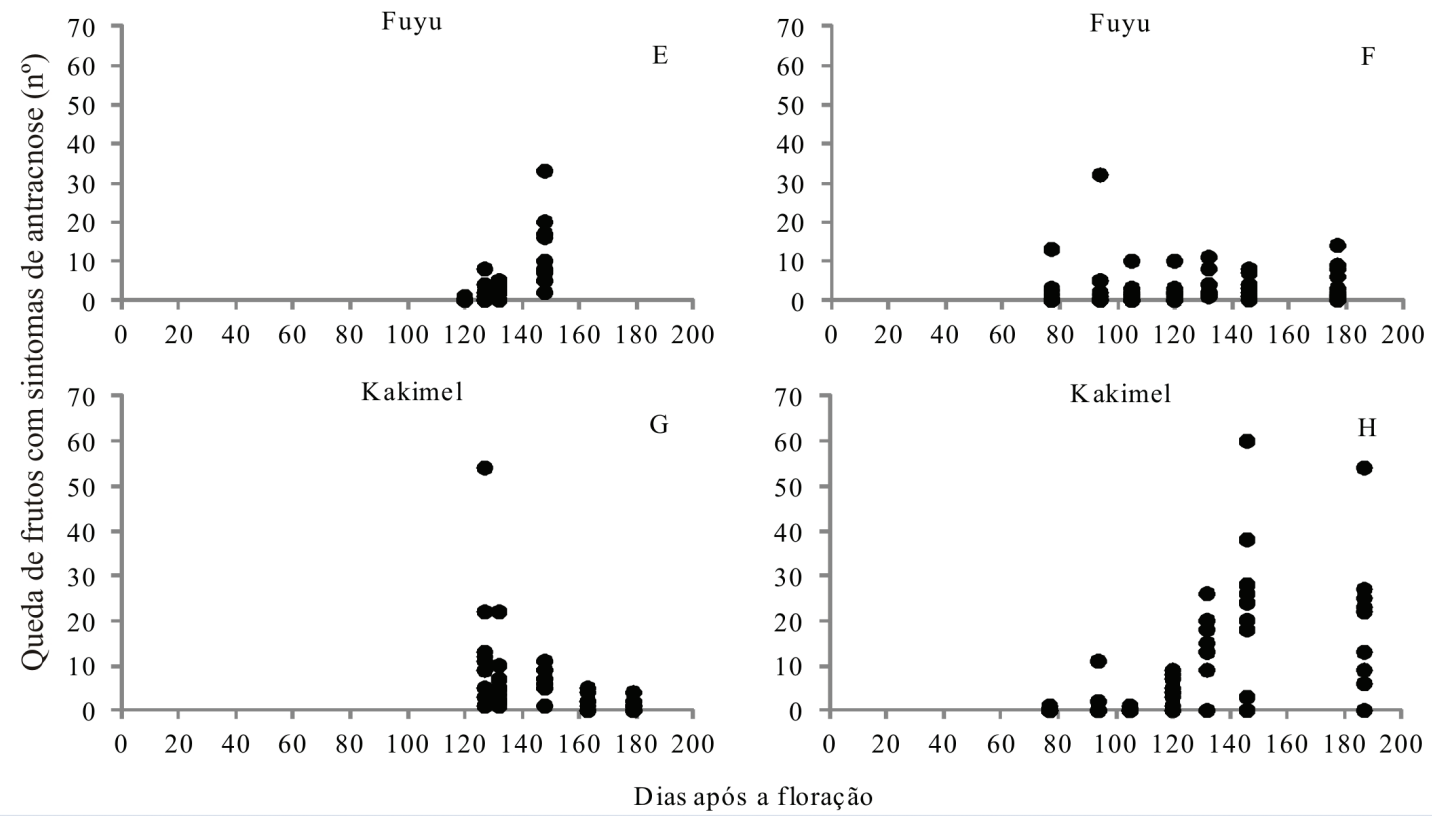

FIGURA 2- Queda de frutos sem (A, B, C e D) e com sintomas (E, F, G e H) de antracnose $\left(\mathrm{n}^{\circ}\right)$ nas 10 plantas selecionadas das cultivares Fuyu e Kakimel cultivadas sob sistema orgânico e convencional, respectivamente, em Campina Grande do Sul, região metropolitana de Curitiba, no Paraná, Brasil, nas safras de 2010/2011 e 2011/2012. A. e E. Fuyu, safra de 2010/2011, B. e F. Fuyu, safra de 2011/2012, C. e G. Kakimel, safra de 2010/2011, D. e H. Kakimel. 
TABELA 2- Incidência de antracnose (\%) em frutos de caqui cv. Fuyu e cv. Kakimel cultivados sob sistema orgânico e convencional, respectivamente, em pomares de Campina Grande do Sul, região metropolitana de Curitiba, no Paraná, Brasil, nas safras de 2010/2011 e 2011/2012.

\begin{tabular}{|c|c|c|c|c|c|c|c|c|}
\hline \multirow{3}{*}{$\begin{array}{l}\text { Dias após } \\
\text { colheita }\end{array}$} & \multicolumn{4}{|c|}{ cv. Fuyu } & \multicolumn{4}{|c|}{ cv. Kakimel } \\
\hline & \multicolumn{2}{|c|}{ Desinfestados $^{\mathrm{y}}$} & \multicolumn{2}{|c|}{ Não desinfestados } & \multicolumn{2}{|c|}{ Desinfestados $^{y}$} & \multicolumn{2}{|c|}{ Não desinfestados } \\
\hline & $2010 / 11$ & $2011 / 12$ & $2010 / 11$ & $2011 / 12$ & $2010 / 11$ & $2011 / 12$ & $2010 / 11$ & $2011 / 12$ \\
\hline 9 & 11 & 3 & 0 & 4 & 0 & 1 & 0 & 0 \\
\hline 13 & 11 & 4 & 1 & 7 & 3 & 1 & 2 & 0 \\
\hline 18 & 12 & 4 & 4 & 7 & 3 & 1 & 5 & 0 \\
\hline
\end{tabular}

${ }^{y}$ Desinfestação realizada em $10 \mathrm{~L}$ de solução com $160 \mathrm{~mL}$ de hipoclorito de sódio a $0,525 \%+160 \mathrm{~mL}$ de etanol a $92,5{ }^{\circ} \mathrm{GL}+0,5 \mathrm{~mL}$ de Tween 20, por 4 minutos, seguida de lavagem em água destilada e esterilizada.

\section{CONCLUSÃO}

Colletotrichum horii é capaz de infectar flores, permanecer latente em frutos verdes e provocar sintomas de antracnose em frutos imaturos, podendo causar danos em pós-colheita. No campo, para cultivares Fuyu e Kakimel, ocorre queda de frutos com sintomas de antracnose entre os meses de janeiro e abril.

\section{AGRADECIMENTOS}

À CAPES, pela concessão de bolsa de mestrado por 12 meses ao primeiro autor, e aos produtores pela total colaboração, fornecendo os pomares para o desenvolvimento da pesquisa.

\section{REFERÊNCIAS}

AGROFIT. Sistema de agrotóxicos fitossanitários. Brasília: Ministério da Agricultura, Pecuária e Abastecimento. Disponível em: http://agrofit. agricultura.gov.br/agrofit cons/principal agrofit cons. Acesso em: 16 jul. 2013.

BALTACIOĞLU, H.; ARTIK, N. Study of post harvest changes in the chemical composition of persimmon by HPLC. Turkish Journal of Agriculture and Forestry, Ankara, v.37, p.568-574, 2013.

BRACKMANN, A.; SCHORR, M.R.W.; GASPERIN, A.R. de; VENTURINI, T. L.; PINTO, J. A.V. Controle da maturação de caqui 'Fuyu' com aplicação de aminoetoxivinilglicina e 1-metilciclopropeno Revista Brasileira de Fruticultura, Jaboticabal, v.35, n.4, p.953-961, 2013.

CHEN, Z.; LIANG, J.; ZHANG, C.; RODRIGUES JR., C.J. Epicatechin and catechin may prevent coffee berry disease by inhibition of appressorial melanization of Colletotrichum kahawae. Biotechnology Letters, London, v.28, p.1.637-1.640, 2006.
CORSATO, C.E.; SCARPARE FILHO, J.A.; VERDIAL, M. F. Fenologia do caquizeiro "RamaForte" em clima tropical. Bragantia, Campinas, v.64, p.323-329, 2005.

CUTILLAS-ITURRALDE, A.; ZARRA, I.; LORENCES, E. P. Metabolism of cell wall polysaccharides from persimmon fruit. Pectin solubilization during fruit ripening occurs in apparent absence of polygalacturonase activity. Physiologia Plantarum, Copenhagen, v.89, p.369-375, 1993.

FAO - Food and Agriculture Organization of the United Nations. FAOSTAT: food and agricultural commodities production. 2011. Disponível em: $\mathrm{http}: / /$ faostat.fao.org/site/339/default.aspx. Acesso em: 22 jan. 2013.

GARDIN, J. P. P.; ARGENTA, L. C.; SOUZA, E. L. de; ROMBALDI, C.V.; SOUZA, A. L. K. de. Qualidade de caqui ‘Rama-Forte' após armazenamento refrigerado, influenciada pelos tratamentos 1-MCP e/ou $\mathrm{CO}_{2}$. Revista Brasileira de Fruticultura, Jaboticabal, v.34, n.4, p.1.043-1.050, 2012.

GIN RAZZOUK, P.L. Avaliação fenológica de dez cultivares de caquizeiro Diospyros kaki L. e propagação por estaquia em regiões tropicais. 2007. 104f. Dissertação (Mestrado em Sistemas de Produção) - Faculdade de Engenharia, Universidade Estadual Paulista, Ilha Solteira, 2007.

HYDE, K.D.; CAI, L.; MCKENZIE, E.H.C.; YANG, Y.L.; ZHANG, J.Z.; PRIHASTUTI, H. Colletotrichum: a catalogue of confusion. Fungal Diversity, Hong Kong, v.39, p.1-17, 2009.

IBGE - Instituto Brasileiro de Geografia e Estatística. Produção agrícola Municipal 2011. Disponível em: $<$ http://www.sidra.ibge.gov.br $>$. Acesso em: 22 jul. 2012. 
IPARDES - Instituto Paranaense de Desenvolvimento Econômico e Social. Disponível em: $<$ http://www. ipardes.gov.br/imp/index.php $>$. Acesso em: 22 jul. 2012.

KWON, J.-H.; KIM, J.; CHOI, O.; GANG, G.-H.; HAN, S.; KWAK Y.-S. Anthracnose caused by Colletotrichum horii on sweet persimmon in Korea: Dissemination of conidia and disease development. Journal of Phytopathology, Berlin, v.161,p.497-502, 2013.

LATTANZIO, V.; LATTANZIO, V.M.T.; CARDINALI, A. Role of phenolics in the resistance mechanisms of plants against fungal pathogens and insects. Phytochemistry: Advances in Research, Kerala, p.23-67, 2006.

LUO, Y.; MICHAILIDES, T. J. Factors affecting latent infection of prune fruit by Monilinia fructicola. Phytopathology, St Paul, v.91, p.864-872, 2001.

MAY DE MIO, L.L.,SILVA, F. A., BLOOD, R.Y., FIGUEIREDO, J.A.G. Twig blight and defoliation caused by Colletotrichum horii in persimmons in Brazil. Revista Brasileira de Fruticultura, Jaboticabal, v. 37, n.1, p. 258-262, 2015.

MEJÍA, L.C.; ROJAS, E.I.; MAYNARD, Z.; VAN BAEL, S.; ARNOLD, A.E.; HEBBAR, P.; SAMUELS, G.J.; ROBBINS, N.; HERRE, E.A. Endophytic fungi as biocontrol agents of Theobroma cacao pathogens. Biological Control, Orlando, v.46, p.4-14, 2008.

MOWAT, A.D.; GEORGE, A.P. Persimmon. In: SCHAFFER, B.; ANDERSEN, P. C. (Ed.). Handbook of environmental physiology of fruit crops: temperate crops. Boca Raton: CRC Press, 1994. v.1, cap.8, p.209-232.

PIMENTEL, I.C.; GLIENKE-BLANCO, C.; GABARDO, J.; STUART, R.M.; AZEVEDO, J.L. Identification and colonization of endophytic fungi from soybean (Glycine max (L.) Merril) under different environmental conditions. Brazilian Archives Biology and Technology, Curitiba, v.49, p.705-711, 2006..

PALOU, L.; MONTESINOS-HERRERO, C.; TARAZONA, I.; TABERNER, V. Postharvest anthracnose of persimmon fruit caused by Colletotrichum gloeosporioides first reported in Spain. Plant Disease, St Paul, v.97, p.691, 2013.

PHOTITA, W.; LUMYONG, S.; LUMYONG, P.; MCKENZIE, E.H.C.; HYDE, K.D. Endophytic fungi of wild banana (Musa acuminata) at Doi Suthep-Pui
National park, in Thailand. Mycological Research, Amsterdam, v.105, p.1508-1513, 2001.

PHOTITA, W.; LUMYONG, S.; LUMYONG, P.; MCKENZIE, E.H.C.; HYDE, K.D. Are some endophytes of Musa acuminata latent pathogens? Fungal Diversity, Hong Kong, v.16, p.131-140, 2004.

PROMPUTTHA, I.; LUMYONG， S.; DHANASEKARAN, V.; MCKENZIE, E.H.C.; HYDE, K.D.; JEEWON, R. A phylogenetic evaluation of whether endophytes become saprotrophs at host senescence. Microbial Ecology, New York, v.53, p.579-590, 2007.

R Development Core Team. R: a language and environment for statistical computing. R Foundation for Statistical Computing. 2010. Disponível em: http:// www.R-project.org.

ROMERO, A.; CARRIÓN, G.; RICO-GRAY, V. Fungal latent pathogens and endophytes from leaves of Parthenium hysterophorus (Asteraceae). Fungal Diversity, Hong Konmg, v.7, p.81-87, 2001.

TAIRA, S.; ONO, M.; OTSUKI, M. Effects of freezing rate on astringency reduction in persimmon during and after thawing. Postharvest Biology and Technology, Amsterdam, v.14, p.317-324, 1998.

VILLARINO, M.; SANDÍN-ESPAÑA, P.; MELGAREJO, P.; DE CAL, A. High chlorogenic and neochlorogenic acid levels in immature peaches reduce Monilinia laxa infection by interfering with fungal melanin biosynthesis. Journal of Agricultural and Food Chemistry, Easton, v.59, p.3205-3213, 2011.

WEIR, B.S.; JONHSTON, P.R. Characterisation and neotypification of Gloeosporium kaki Hori as Colletotrichum horii. Mycotaxon, Ithaca, v.111, p.209-219, 2010.

WILLIAMSON, S.M.; SUTTON, T.B. First report of anthracnose caused by Colletotrichum acutatum on persimmon fruit in the United States. Plant Disease, St Paul, v. 94, p. 634-634, 2010.

XIE, L.; ZHANG, J.; CAI, L.; HYDE, D. Biology of Colletotrichum horii, the causal agent of persimmon anthracnose. Mycology, Abingdon, v.1, p.242-253, 2010.

YANG, Y.; WANG, R.; LI, G.; RUAN, X. Observation of persimmom anthracnose in the national field genebank for persimmom. Acta Horticulturae, The Hague, v.833, p.109-112, 2009. 